\title{
Preparation of submicrocrystal Al-Ti-B master alloy and its influence on microstructure and properties of AZ91D
}

\author{
Tian-shun Dong', Xiao-dong Zheng', Xiao-bing Li', *Guo-lu Li', Tuo Wang', and Chun-xiang Cui ${ }^{1,2}$ \\ 1. School of Material Science and Engineering, Hebei University of Technology, Tianjin 300130, China \\ 2. Key Lab. for New Type of Functional Materials of Hebei Province, Hebei University of Technology, Tianjin 300130, China
}

\begin{abstract}
To improve the mechanical properties of AZ91D magnesium alloy, the submicrocrystal Al-Ti-B master alloy was prepared with copper mold inject casting method, and the influence of submicrocrystal Al-Ti-B master alloy on the microstructure and mechanical properties of AZ91D was investigated. Results show that, the distribution of $\mathrm{TiB}_{2}$ phase in submicrocrystal Al-Ti-B alloy is even and disperse, and the average size of $\mathrm{TiAl}_{3}$ phase is reduced from 10-30 $\mu \mathrm{m}$ to $\sim 1 \mu \mathrm{m}$. The properties of AZ91D refined with submicrocrystal Al-Ti-B master alloy are better than that with coarse-grained Al-Ti-B master alloy without copper mold inject casting. The tensile strength, elongation and Brinell hardness of AZ91D are increased by $10.6 \%, 25 \%$ and $18.1 \%$, respectively. Therefore, refinement of AZ91D with submicrocrystal Al-Ti-B that is obtained by copper mold inject casting is an effective method to improve its mechanical properties.
\end{abstract}

Key words: copper mold inject casting; submicrocrystal Al-Ti-B; refinement; AZ91D

CLC numbers: TG146.21 Document code: A Article ID: 1672-6421(2017)06-513-06

$\mathrm{M}$ agnesium alloy has been widely used in the field of transportation, aviation, medical instrument and electronic appliance for its many advantages, such as high specific strength, high specific stiffness, low density, strong shielding of electromagnetic and resistance to radiation, and convenience of cutting and recycling ${ }^{[1-2]}$. The most typical material of $\mathrm{Mg}-\mathrm{Al}$ series magnesium alloy is AZ91D, which has been applied to automobile manufacture extensively ${ }^{[3]}$. Its as-cast microstructure consists of large dendritic $\alpha-\mathrm{Mg}$ and uneven networks $\beta-\mathrm{Mg}_{17} \mathrm{Al}_{12}$ phase ${ }^{[4]}$. Moreover, crystal structure of magnesium is hexagonal close packed (hcp). So the mechanical properties of AZ91D such as strength, hardness and plasticity are poor, which limits its applications to a great extent.

\section{*Tian-shun Dong}

Male, born in 1968, Associate Professor. His research interests mainly focus on material forming technology.

E-mail: dongtianshun111@163.com

*Corresponding author: Guo-lu Li, E-mail: liguolu0305@163.com

Received: 2017-03-29; Accepted: 2017-08-15
According to the Hall-Petch formula, the finer the grains is, the higher the strength and hardness of material are. With the grain refinement, the capability of plastic deformation of polycrystalline magnesium will be better ${ }^{[5]}$. Therefore, refining grains to change the morphology, size and distribution of both $\alpha-\mathrm{Mg}$ and $\beta-\mathrm{Mg}_{17} \mathrm{Al}_{12}$ phases, is an effective way to improve the properties of AZ91D alloy. At present, the refinement of magnesium alloy with massive or rod like master alloy with coarse grains has been proposed or reported in some literatures ${ }^{[6]}$. However, no matter what refiner is used, the properties of magnesium alloys are difficult to be further improved ${ }^{[7-8]}$. Al-Ti-B master alloy, which is commonly used as grain refiner for aluminum alloy, is seldom applied to magnesium alloy. Further more, there appears to be few studies on magnesium alloys being refined by submicrocrystal Al-Ti-B master alloy ${ }^{[9]}$. In this work, submicrocrystal Al-Ti-B master alloy has been prepared by copper mold inject casting method, with which the melt of AZ91D is dealt subsequently, in order to study the influence of submicrocrystal Al-Ti-B master alloy on the microstructure and performance of AZ91D. 


\section{Materials and procedures}

\subsection{Preparation of submicrocrystal Al-Ti-B master alloy}

The study used a kind of commercial rod-like (diameter $9.5 \mathrm{~mm}$ ) Al-Ti-B master alloy as the refiner, and its composition is shown in Table 1. The process of copper mold injection casting was conducted in a vacuum induction furnace. The basic principles are as follows. First of all, the Al-Ti-B master alloy was cut into small pieces and placed in a quartz tube. Subsequently, the chamber of the induction furnace was pulled to vacuum and filled with high-purity argon. After that, the small pieces AlTi-B master alloy was melted by the heat generated from high frequency induction. Finally, the metal melt was injected into the copper mold under the pressure of high-purity argon, and then the submicrocrystal Al-Ti-B master alloy with a diameter of $3 \mathrm{~mm}$ was obtained. Because the submicrocrystal Al-Ti-B master alloy was prepared under the protection of high-purity argon, and the melting time was very short, which resulted in little evaporation and burning loss of element, the chemical compositions of the submicrocrystal Al-Ti-B master alloy are not given additionally in this paper.

Table 1: Chemical composition of Al-Ti-B master

\begin{tabular}{ccccc} 
Ti & B & Fe & Si & Al \\
\hline 5.40 & 1.04 & 0.08 & 0.10 & Bal.
\end{tabular}

\subsection{Melting and refining of AZ91D}

In this study, AZ91D ingots used in the present research were from the Japanese Datong Company. The AZ91D magnesium alloy was melted in a well-type resistance furnace, and 3\% $\mathrm{SF}_{6}$ $+97 \% \mathrm{CO}_{2}$ was used as shielding gas. Small massive AZ91D ingots of $300 \mathrm{~g}$ in a graphite crucible were melted and heated to $760{ }^{\circ} \mathrm{C}$. After that, the $0.4 \mathrm{wt} . \% \mathrm{Al}-\mathrm{Ti}-\mathrm{B}$ master alloy refiner was added and AZ91D melt was agitated with a carbon rod. Then the melt was cooled to $720{ }^{\circ} \mathrm{C}$ and kept static for 10 minutes subsequently. Finally, after slag removal, the magnesium melt was poured into a metal mould preheated at $200{ }^{\circ} \mathrm{C}$ in a resistance furnace. After solidification, AZ91D casting rods of $\Phi 25 \mathrm{~mm} \times 180 \mathrm{~mm}$ were obtained, whose upper part was coneshape runner cup, and the tensile sample was cut at the bottom. The size of tensile sample is shown in Fig. 1.

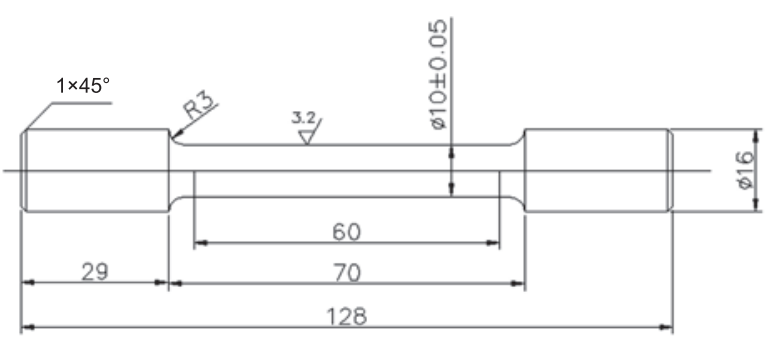

Fig. 1: Size of tensile sample

\subsection{Testing and analysis}

The microstructure of Al-Ti-B master alloy was observed and analyzed using a Hitachi S4800 scanning electron microscope. The phase structure of Al-Ti-B master alloy was determined using a Bruker D8 Focus $\mathrm{X}$ ray diffractometer. The as-cast microstructure of AZ91D refined by A1-Ti-B master alloy was observed on a Nikon ECLIPSE MA100 metalloscope (OM) And the tensile properties and Brinell hardness were tested by a SHT-5303 microcomputer controlled electro-hydraulic servo universal testing machine and a HB-3000 Brinell hardness tester, respectively

\section{Results and analysis}

\subsection{Analysis of Al-Ti-B master alloy microstructure}

The microstructure of Al-Ti-B master alloy is shown in Fig. 2. Figure 2(a) shows that the second phases $\mathrm{TiB}_{2}$ in the Al-Ti-B master alloy without copper mold inject casting display obvious agglomeration and uneven distribution phenomenon. Coarse and blocky $\mathrm{TiAl}_{3}$ phase exists in the matrix, its average size is about 10-30 $\mu \mathrm{m}$. Figure 2(b) indicates that the average size of $\mathrm{TiB}_{2}$ phase in the Al-Ti-B alloy is between $0.5 \mu \mathrm{m}$ and $1 \mu \mathrm{m}$. However, it can be seen from Fig. 2(c) and Fig. 2(d) that, the second phases $\mathrm{TiB}_{2}$ in the Al-Ti-B alloy obtained through copper mold inject casting present no agglomeration phenomenon, and their distribution is homogeneous. EDS analysis result of point A in Fig. 2(d) is shown in Fig. 2(e). It can be seen from Fig. 2(d) and Fig. 2(e) that the dimension of $\mathrm{TiAl}_{3}$ phase was decreased dramatically to $\sim 1 \mu \mathrm{m}$, while the dimension of hexagonal $\mathrm{TiB}_{2}$ phase has little change. These indicate that the second phases in Al-Ti-B alloy have been refined or homogenized obviously. In conclusion, coarse grained Al-Ti-B master alloy was translated to submicrocrystal Al-Ti-B master alloy by copper mold inject casting method.

\subsection{XRD analysis of Al-Ti-B master alloy}

$\mathrm{XRD}$ analysis results of Al-Ti-B master alloy are shown in Fig. 3. It can be seen from Fig. 3 that the Al-Ti-B mainly includes two kinds of second phases, i.e. $\mathrm{TiB}_{2}$ and $\mathrm{TiAl}_{3}$, which can further confirm that the hexagonal second phase and blocked second phase in Fig. 2(a) are $\mathrm{TiB}_{2}$ and $\mathrm{TiAl}_{3}$, respectively. Compared with Fig. 3(b), the peak in Fig. 3(a) is higher and the wave width is narrower. But, there is a higher and wider wave peak on the left side of Fig. 3(b). The Scherrer equation is shown as follows:

$$
D=\frac{K \gamma}{B \cos \theta}
$$

where $K$ is a constant, $D$ is grain size, $B$ is diffraction peak width at half height, $\theta$ is diffraction angle, $\gamma$ is wave length of $\mathrm{X}$ ray. As indicated in equation 1 , the grain size $D$ will be smaller if the diffraction peak width at half height $B$ is larger. This 

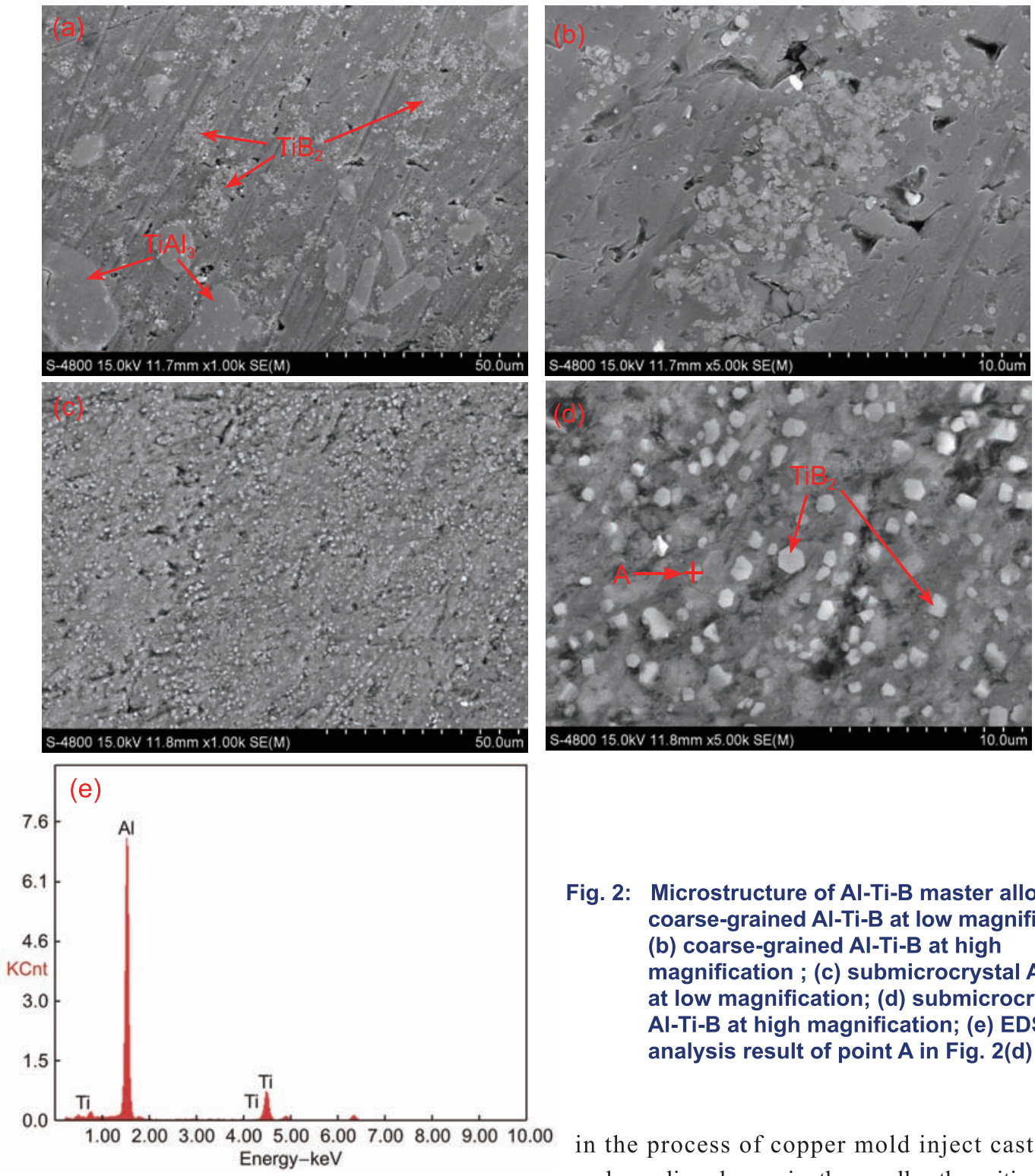

Fig. 2: Microstructure of Al-Ti-B master alloy: (a) coarse-grained Al-Ti-B at low magnification (b) coarse-grained Al-Ti-B at high magnification ; (c) submicrocrystal Al-Ti-B at low magnification; (d) submicrocrystal Al-Ti-B at high magnification; (e) EDS analysis result of point $A$ in Fig. 2(d)

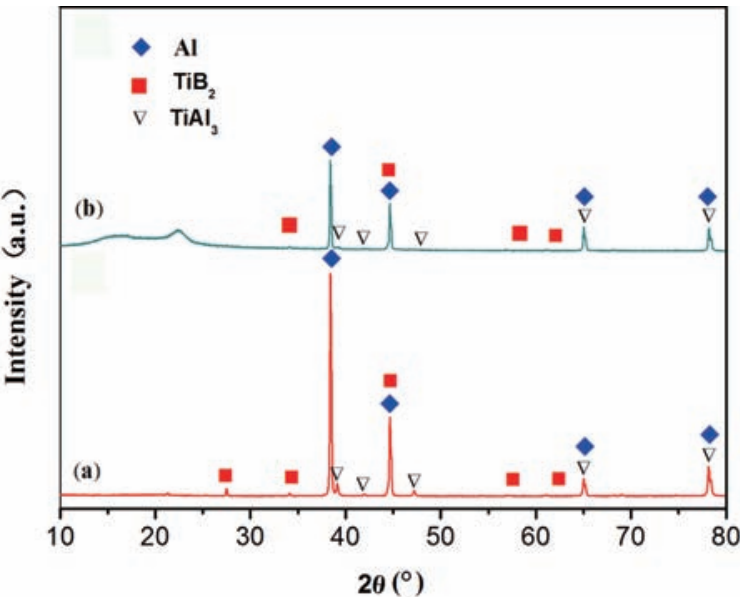

Fig. 3: XRD results of Al-Ti-B master alloys: (a) coarsegrained Al-Ti-B; (b) submicrocrystal Al-Ti-B

implies that the submicrocrystal Al-Ti-B master alloy has finer microstructure than that of coarse grained Al-Ti-B master alloy. From the crystallization thermodynamics point of view, the reason for above is that large undercooling degree was produced

in the process of copper mold inject casting. The higher undercooling degree is, the smaller the critical nucleus radius and the crystal grains are; hence, the size of the second phases is smaller. Therefore, the decrease of the size of $\mathrm{TiAl}_{3}$ in $\mathrm{Al}-$ Ti-B master alloy after copper mold inject casting results in the decrease of its diffraction peak height. But the change of $\mathrm{TiB}_{2}$ is mainly embodied in the dispersion degree, instead of its size; therefore, the slight decrease of the peak height of $\mathrm{TiB}_{2}$ in Fig. 3 may be caused by the slight deposition of $\mathrm{TiB}_{2}$ in the remelting during the process of copper mold inject casting.

\subsection{Analysis of AZ91D metallographic structure}

AZ91D alloy is one of the most widely used alloys in $\mathrm{Mg}-\mathrm{Al}$ system. According to Mg-Al binary alloy phase diagram ${ }^{[10]}$, the structure obtained under non-equilibrium crystallization conditions is mixture of $\alpha-\mathrm{Mg}$ and $\beta-\mathrm{Mg}_{17} \mathrm{Al}_{12}$, while $\beta-\mathrm{Mg}_{17} \mathrm{Al}_{12}$ is the strengthening phase of AZ91D alloy ${ }^{[11-12]}$.

Figure 4(a)-(c) show as-cast microstructure of AZ91D under different refining conditions. Figure 4(a) is as-cast metallographic structure of AZ91D without refinement. Most parts in the figure are light white $\alpha-\mathrm{Mg}$ matrix with coarse 
grains. Reticular $\beta-\mathrm{Mg}_{17} \mathrm{Al}_{12}$ strengthening phase with larger size precipitated in a discontinuous and obviously uneven manner along $\alpha-\mathrm{Mg}$ grain boundaries. Figure $4(\mathrm{~b})$ is as-cast metallographic structure of AZ91D with $0.4 \mathrm{wt} . \%$ coarse-grained Al-Ti-B master alloy. Compared with Fig. 4(a), $\alpha-\mathrm{Mg}$ matrix and $\beta-\mathrm{Mg}_{17} \mathrm{Al}_{12}$ phase in Fig. 4(b) were refined significantly. And $\beta-\mathrm{Mg}_{17} \mathrm{Al}_{12}$ phase is spherical with smaller size, most of which distributes in $\alpha-\mathrm{Mg}$ matrix evenly and dispersedly. Figure 4(c) is as-cast metallographic structure of AZ91D with 0.4wt.\% submicrocrystal Al-Ti-B master alloy. Compared with Fig. 4(b), $\alpha-\mathrm{Mg}$ matrix structure and $\beta-\mathrm{Mg}_{17} \mathrm{Al}_{12}$ phase were refined further, most of $\beta-\mathrm{Mg}_{17} \mathrm{Al}_{12}$ phase are dot shape, and their distribution in $\alpha-\mathrm{Mg}$ matrix is more even and disperse.

In order to further show the refining effects of two refiners on $\alpha-\mathrm{Mg}$ matrix of AZ91D, three samples above were heat treated by $420^{\circ} \mathrm{C} \times 8 \mathrm{~h}+200^{\circ} \mathrm{C} \times 1 \mathrm{~h}$, and the metallographic structure after heat treatment is shown in Fig. 4(d)-(f). The average grain size of each of the three samples was obtained by repeating measuring and averaging the results, which were $24.3 \mu \mathrm{m}, 15.8$ $\mu \mathrm{m}$ and $10.2 \mu \mathrm{m}$, respectively. The result indicates that the grain size of $\alpha-\mathrm{Mg}$ phase in AZ91D obviously become smaller after the addition of Al-Ti-B. While, in contrast, the grain size of the alloy refined with the submicrocrystal Al-Ti-B master alloy is smaller than that with coarse-grained Al-Ti-B master alloy.

\subsection{Mechanical properties of AZ91D}

Figure 5 is the average of tensile strength and elongation of as-cast AZ91D specimens. The results show that the tensile strength, especially elongation of the as-cast AZ91D has been improved after refinement treatment. As for AZ91D, added coarse grained Al-Ti-B, the tensile strength increases from 157.1 $\mathrm{MPa}$ to $179.2 \mathrm{MPa}$, and the elongation increases from $1.88 \%$ to $2.54 \%$. Tensile strength and elongation of AZ91D with submicrocrystal Al-Ti-B increase to $195.8 \mathrm{MPa}$ and
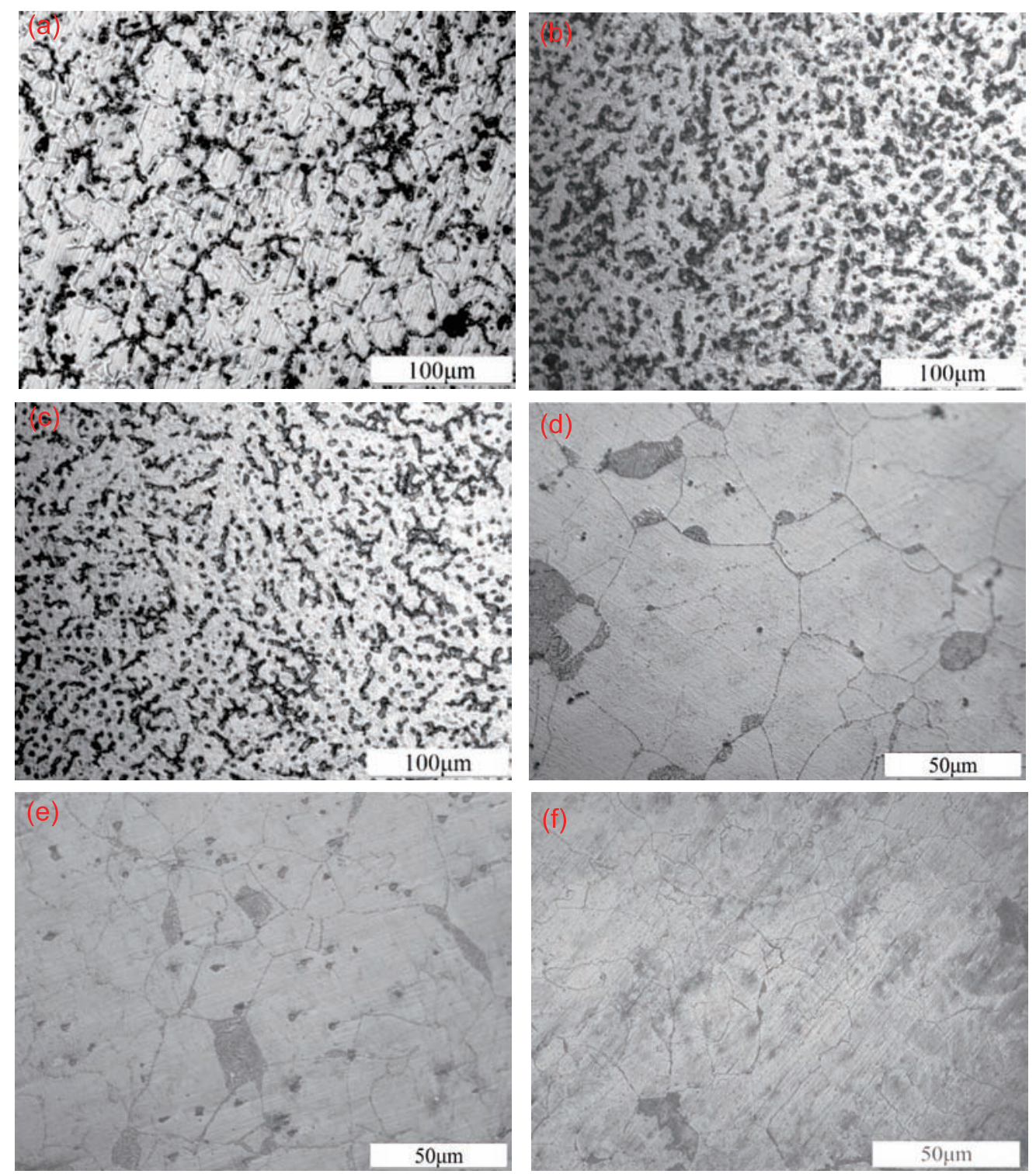

Fig. 4: As-cast microstructures of AZ91D: (a) without refinement, (b) with $0.4 \mathrm{wt} . \%$ coarse-grained Al-Ti-B , (c) with $0.4 \mathrm{wt} . \%$ submicrocrystal Al-Ti-B; and heat treated microstructures of AZ91D: (d) without refinement, (e) refined with $0.4 \mathrm{wt} . \%$ coarse-grained Al-Ti-B, (f) refined with $0.4 \mathrm{wt}$. \% submicrocrystal Al-Ti-B 


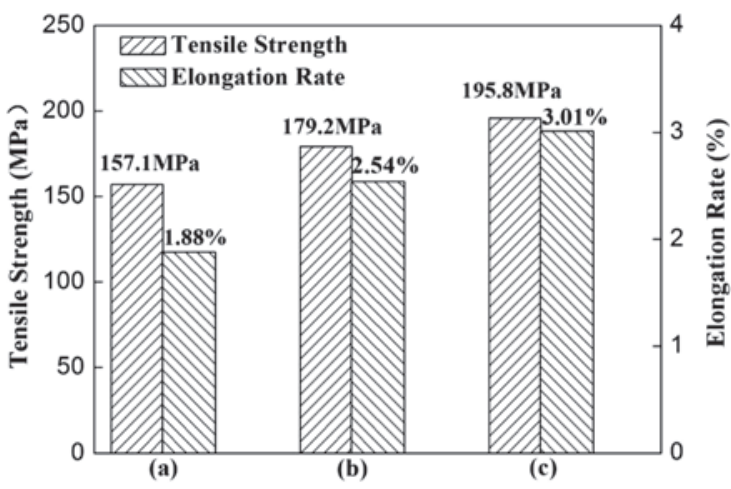

Fig. 5: Tensile strength and elongation of AZ91D magnesium alloy: (a) without refinement; (b) with 0.4 wt. \% coarse-grained Al-Ti-B; (c) with 0.4 wt.\% submicrocrystal Al-Ti-B

$3.01 \%$, respectively. It is well known that grain refinement is an effective method to improve material's strength without decreasing elongation. The smaller the grain is, the less the amount of piled up dislocations and the stress concentration in alloy are ${ }^{[13]}$. Only under larger external force, the slip system of adjacent grains can be initiated, then the strength is enhanced. Considering the action of grain boundary to dislocation slip, with the size of grain decreasing, the boundary area and slip resistance to dislocation increase, which will cause high strength. In addition, magnesium is hexagonal close packed structure with less slip system, hence, the increase in finer grains will make the dislocation more difficult to slip, so that the tensile strength of alloy is improved. At the same time, the finer the grain is, the larger the number of grains in a given alloy is. Thus, under the same deformation, the deformation will be conducted in more grains and the alloy deformation will be more even macroscopically, which will increase the plastic property of AZ91D magnesium alloy.

Figure 6 is the average measurement value of Brinell hardness of AZ91D sample. As shown in the figure, Brinell hardness of AZ91D magnesium alloy after refinement treatment was enhanced significantly. Brinell hardness of AZ91D refined with coarse grained Al-Ti-B increases from 66 to $80 \mathrm{HB}$, while Brinell hardness of AZ91D refined with submicrocrystal AlTi-B increases to $92 \mathrm{HB}$. This shows that after the refinement treatment, the hardness of AZ91D increases dramatically. For AZ91D refined with submicrocrystal Al-Ti-B, the finer $\alpha-\mathrm{Mg}$ grains results in the increase of the total area of grain boundary, where $\beta-\mathrm{Mg}_{17} \mathrm{Al}_{12}$ phase is evenly distributed, thus the dislocation glide consumes more energy while passing the second phase. This provides larger obstruction to dislocation movement and the deformation resistance of material becomes larger correspondingly ${ }^{[13]}$. Macroscopically, it is not easy to produce plastic deformation, thus makes the hardness of AZ91D refined with submicrocrystal Al-Ti-B increase more significantly.

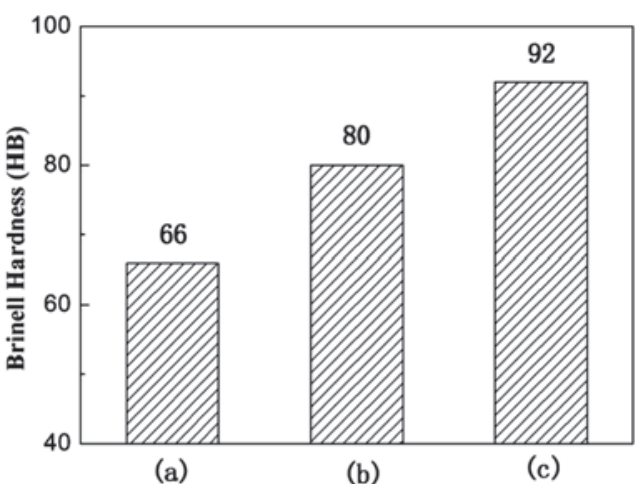

Fig. 6: Brinell hardness of AZ91D sample: (a) without refinement; (b) refined by $0.4 \mathrm{wt}$. \% coarse -grained Al-Ti-B; (c) refined by $0.4 \mathrm{wt} . \%$ submicrocrystal AlTi-B

\section{Mechanism analysis}

The melting point of $\mathrm{TiB}_{2}$ phase in Al-Ti-B alloy is $2,980{ }^{\circ} \mathrm{C}^{[14]}$. Therefore, $\mathrm{TiB}_{2}$ would not be melted in the melting process of magnesium alloy. At the same time, crystal structure of both $\mathrm{TiB}_{2}$ and magnesium are hexagonal close-packed structure. The lattice constants of $\mathrm{TiB}_{2}(\mathrm{a}=0.303034 \mathrm{~nm}, \mathrm{c}=0.3231 \mathrm{~nm})$ are near to those of $\alpha-\mathrm{Mg}(\mathrm{a}=0.3203 \mathrm{~nm}, \mathrm{c}=0.5200 \mathrm{~nm})$. According to the equation of mismatch degree:

$$
\delta=\frac{\Delta \mathrm{a}_{0}}{\mathrm{a}_{0}} \times 100 \%
$$

where $\Delta \mathrm{a}_{0}$ indicates the difference of lattice constant of low index crystal plane of matrix and nucleation solid phase, $a_{0}$ is the lattice constant of nucleation phase, the lattice mismatch degree of (0001) surface of $\mathrm{TiB}_{2}$ and that of $\alpha-\mathrm{Mg}$ matrix is $5.39 \%$. The nucleation is most effective when $\delta<6 \%$, the nucleation is intermediate effective when $\delta=6 \%-15 \%$, and the nucleation is invalid when $\delta>15 \%{ }^{[15]}$. So, $\mathrm{TiB}_{2}$ phase meets heterogeneous nucleation requirements of $\alpha-\mathrm{Mg}$ matrix, and can be nucleus of $\alpha-\mathrm{Mg}$. Therefore, after Al-Ti-B master as a refiner was added in magnesium alloy, $\mathrm{TiB}_{2}$ in refiner can effectively increase the nucleation rate of $\alpha-\mathrm{Mg}$ and refine the grains. $\mathrm{TiAl}_{3}$ is bodycentered tetragonal structure $(\mathrm{a}=0.3848 \mathrm{~nm}, \mathrm{c}=0.857 \mathrm{~nm})$, lattice mismatch degree between $\mathrm{TiAl}_{3}$ and $\alpha-\mathrm{Mg}$ is $20.14 \%$; $\beta-\mathrm{Mg}_{17} \mathrm{Al}_{12}$ is body-centered cubic structure $(\mathrm{a}=1.05438 \mathrm{~nm})$, lattice mismatch degree between $\mathrm{TiAl}_{3}$ and $\beta-\mathrm{Mg}_{17} \mathrm{Al}_{12}$ is $23.03 \%$, which means $\mathrm{TiAl}_{3}$ would not become heterogeneous nucleation sites of $\alpha-\mathrm{Mg}$ and $\beta-\mathrm{Mg}_{17} \mathrm{Al}_{12}$. But the melting point of $\mathrm{TiAl}_{3}$ is $1,373{ }^{\circ} \mathrm{C}{ }^{[16]}$, it could be enriched at the frontier of solid-liquid interface, hindering the grain growth of $\beta-\mathrm{Mg}_{17} \mathrm{Al}_{12}$. The combined action of above two factors led to refinement of $\alpha-\mathrm{Mg}$ matrix and $\beta-\mathrm{Mg}_{17} \mathrm{Al}_{12}$ phase in AZ91D alloy. But if the refiner is added excessively, $\mathrm{TiB}_{2}$ tends to aggregate because of its finer size and larger surface energy. The amount of $\mathrm{TiB}_{2}$ as heterogeneous nucleus was reduced. Thus, the refining effect was worsened ${ }^{[17]}$. 
When equal amount of submicrocrystal refiner and coarsegrain refiner are added, respectively, into the melt of AZ91D, the size of $\mathrm{TiB}_{2}$ and $\mathrm{TiAl}_{3}$ in the former is finer and the quantity is greater, thus $\mathrm{TiB}_{2}$ and $\mathrm{TiAl}_{3}$ is likely to diffuse in $\mathrm{AZ91D}$ melt and be distributed uniformly. Therefore, the refining effect of submicrocrysta refiner for AZ91D is better than that of coarsegrain refiner.

In fact, it can be seen from this work that the influence of Al-Ti-B master alloy with different microstructures on AZ91D exhibits noticeable metal genetics effect, which is specifically embodied in the dispersion degree of $\mathrm{TiB}_{2}$ and size of $\mathrm{TiAl}_{3}$.

\section{Conclusions}

(1) Submicrocrystal Al-Ti-B master alloy can be obtained by copper mold inject casting. The distribution of the second phases $\mathrm{TiB}_{2}$ in the submicrocrystal Al-Ti-B alloy is even and disperse, and the average size of $\mathrm{TiAl}_{3}$ phases is reduced from $10-30 \mu \mathrm{m}$ (coarse-grained Al-Ti-B master alloy) to $\sim 1 \mu \mathrm{m}$. The grains of Al-Ti-B refiner are refined obviously.

(2) The tensile strength, elongation and Brinell hardness of AZ91D refined with submicrocrystal Al-Ti-B increase by $10.6 \%, 25 \%$ and $18.1 \%$, respectively, than those of AZ91D refined with coarse grained Al-Ti-B. Therefore, submicrocrystal Al-Ti-B master alloy that is obtained through copper mold inject casting method is more effective on refinement of AZ91D alloy.

\section{References}

[1] Luo H J, Song B N, Liu Y H, et al. Electroless Ni-P plating on $\mathrm{Mg}$-Li alloy by two-step method. Transactions of Nonferrous Metals Society of China, 2011, 21(10): 2225-2230.

[2] Jiang Su-qin, Zhou Jian-zhong, Wu Jian-hua, et al. Research on fatigue properties of ZK60 wrought magnesium alloy treated by laser shot peening. Laser \& Optoelectronics Progress, 2012, 49(8): 081403. (In Chinese)

[3] Tamura $\mathrm{Y}$, Kida $\mathrm{Y}$, Tamehiro $\mathrm{H}$, et al. The effect of manganese on the precipitation of $\mathrm{Mg}_{17} \mathrm{Al}_{12}$ phase in magnesium alloy AZ91D. Materials Science, 2008, 43 (4): 1249-1258.
[4] Fei Xu, Ren Aiguo, Gu Yongyu, et al. Effects of laser shock processing on mechanical properties of AZ91D magnesium alloy. Laser Technology, 2010, 34(4): 552-556.

[5] Kun Yu, Shou-tai Rui, Jue-min Song, et al. Effects of grain refinement on mechanical properties and microstructures of AZ31 alloy. Transactions of Nonferrous Metals Society of China, 2008, 18 (Supplement 1): s39-s43.

[6] Han Hui, Chen Yang, Liu Sheng-fa, et al. Grain refinement of AZ91D magnesium alloy by $\mathrm{Mg}-\mathrm{TiB}_{2}$ master alloy and $\mathrm{Ce}$. China Foundry, 2010, 59(4): 404-407.

[7] Wang Bin, Yang Yuan-sheng, Zhou Ji-xue, et al. Microstructure refinement of AZ91D alloy solidified with pulsed magnetic field. Transactions of Nonferrous Metals Society of China, 2008, 18(3): 536-540.

[8] Chen T J, Wang R Q, Ma Y, et al. Grain refinement of AZ91D magnesium alloy by Al-Ti-B master alloy and its effect on mechanical properties. Materials and Design, 2012, 34: 637648.

[9] Liao Cheng-wei, Li Yang, Tu Rui, et al. Preparation of high purity Al-5Ti-B grain refiner and its microstructure characteristics. Special Casing \& Nonferrous Alloys, 2012, 32(3): 203-207. (In Chinese)

[10] Chen Li-juan. Thermodynamic study of the phase ewuilibria in the Mg-Al, Mg-Zn based alloys. Master' thesis, Shenyang: Northeastern University, 2010: 20. (In Chinese)

[11] Shi Hui-ying, Chen Zi-shan, Zhang Ju-mei, et al. Effects of precipitation morphology of $\beta-\mathrm{Mg}_{17} \mathrm{Al}_{12}$ phase on mechanical properties of AZ91D magnesium alloy. Heat Treatment of Metals, 2010, 35(1): 42-46. (In Chinese)

[12] Tamura $\mathrm{Y}$, Kida $\mathrm{Y}$, Tamehiro $\mathrm{H}$, et al. The effect of manganese on the precipitation of $\mathrm{Mg}_{17} \mathrm{Al}_{12}$ phase in magnesium alloy AZ91D. Materials Science, 2008, 43 (4): 1249-1258.

[13] Cui Zhong-qi, Qin Yao-kun. Metallography and heat treatment. Beijing: China Machine Press, 2008. (In Chinese)

[14] Li P T, Ma X G, Li Y G, et al. Effects of trace C addition on the micro-structure and refining efficiency of Al-Ti-B master alloy. Journal of Alloys and Compounds, 2010, 503: 286-290.

[15] Matucha K H. Structure and properties of nonferrous alloy. Beijing: Science Press, 1999. (In Chinese)

[16] Chu M S, Wu S K. Oxidation behavior of Ti-50Al intermetallics with thin $\mathrm{TiAl}_{3}$ film at $1000{ }^{\circ} \mathrm{C}$. Oxidation of Metals, 2005, 63(1/2): 113.

[17] Wang Rui-quan, Qiu Jia-fei, Zhang Wei, et al. Refining Technology of AM60B Alloy with Al5Ti1B. Hot Working Technology, 2013, 42(1): 51-55. (In Chinese) 